\title{
Omission of the Bladder Flap Suggests Short Term and Long Term Benefits
}

\author{
Mona Omar, Manal A. Farahat \\ Tanta University Faculty of Medicine, Department of Obstetrics and Gynecology, Tanta, Egypt \\ Email: Momar14101976@gmail.com
}

How to cite this paper: Omar, $M$. and Farahat, M.A. (2019) Omission of the Bladder Flap Suggests Short Term and Long Term Benefits. Open Journal of Obstetrics and Gynecology, 9, 566-577. https://doi.org/10.4236/ojog.2019.95055

Received: March 18, 2019

Accepted: May 5, 2019

Published: May 8, 2019

Copyright (c) 2019 by author(s) and Scientific Research Publishing Inc. This work is licensed under the Creative Commons Attribution International License (CC BY 4.0).

http://creativecommons.org/licenses/by/4.0/ c) (i) Open Access

\begin{abstract}
Background: Cesarean section is now the most common major surgical procedure performed on women worldwide. With the increasing numbers of cesarean sections, there is the need to utilize evidence based techniques to optimize outcomes and minimize complications. We hypothesize that omission of the bladder flap in both primary and repeat cesarean sections will be associated with shorter operating time without a significant increase in intraoperative and postoperative complications. Methods: 550 patients were enrolled in the study. They were randomly allocated in the 2 groups to evaluate the effects of cancelling the bladder dissection. Results: Significant reduction of the total operating time $(p=0.01)$, skin to delivery time $(p=0.02)$ and micro-hematuria $(\mathrm{p}=0.01)$ in group with bladder omission. Long term result. Including more bladder adhesion and fibrosis in the cases with bladder dissection. Conclusions: Omission of the bladder dissection achieved short-term advantages as regards reduction of operating time, incision-delivery duration and decreased blood loss as well as long-term effects include different in the bladder adhesion.
\end{abstract}

\section{Keywords}

Cesarean Section, Bladder Flap, Adhesion, Operative Time

\section{Introduction}

Cesarean delivery is the most common major surgical procedure in women worldwide. The rate of cesarean delivery is increasing continuously and has reached more than $30 \%$ in several countries [1] [2] [3]. In order to minimize complications of the CS and optimize outcomes, there is the need to utilize evidence based techniques in performing this procedure. Recently, evidence base has been made for simplifying the procedure by eliminating unnecessary and 
potentially harmful steps [4]. To reduce maternal and neonatal morbidity, several studies have addressed the role of the surgical technique at the time of caesarean delivery, including manual placental removal, uterine exteriorization, subcutaneous tissue re-approximation and single-versus double-layer uterine incision closure, to the minimization of infectious morbidity and uterine rupture [5] [6] [7] [8]. Multiple caesarean deliveries increase the risk of postoperative pelvic and abdominal adhesions that will result in increased time required to deliver the newborn, operative blood loss and the occurrence of bladder injury [9] [10] [11].

Formation of a bladder flap is one of the standard stages in CS. The aim of the flap is to create more access to the lower uterine segment in addition to reducing the risk of damage to the bladder during CS [12] [13]. Bladder flap is created through the cutting surface of the visceral peritoneum in order to isolate the bladder from the lower uterine segment. If the uterine incision is made slightly above the vesico-uterine peritoneal fold, the loose connective tissue between the uterus and the urinary bladder allows the spontaneous descent of the bladder.

Despite the description of a cesarean technique to eliminate "unnecessary" steps during routine cesareans, obstetricians continue to create bladder flaps on a routine basis. Also, in a meta-analysis published in 2014, it was demonstrated that the formation of a bladder flap will not lead to significantly improved outcomes of CS, and on the other hand, it can prolong the delivery time and, therefore, non-formation of the bladder flap is more advisable [14]. Previous study, reported benefits, including a decreased incision to delivery interval, total operating time, blood loss, microhematuria, and analgesia requirement when the bladder flap was omitted [15]. Also omission of the bladder flap prevents the incision from being made too low, which prevents rupture of cervix when it is fully effaced and dilated. Bladder injuries are rare complications of cesarean, but when they occur, they are usually caused by surgical difficulty encountered while developing the bladder flap [16].

The theory of omission of the bladder flap in CS delivery has a long history, and the majority of previous studies have examined the effects of this action in short intervals. This study has noted that the number of intervention studies conducted for comparing the two techniques of formation or non-formation of bladder flap at CS is low and more research should be carried out in this area. Inclusion of both primary and repeat cesarean deliveries also enabled us estimate whether the benefits or risks of omitting the bladder flap differ for primary and repeat cesarean deliveries. Also, more studies are needed to evaluate the long period effect of bladder flap omission.

\section{Patient and Method}

This was a randomized controlled clinical trial comparing the effects of omitting the bladder flap from the standard cesarean delivery technique from the period January 2016 to January 2019. The study was approved by Tanta University hos- 
pital ethical committee. This study conducted on pregnant women undergone CS in Tanta university hospital.

\subsection{Inclusions Exclusions Characters}

Women undergoing primary or repeat cesarean delivery at gestational age of 32 weeks of gestation or more were eligible. Women undergoing emergent cesarean deliveries, planned vertical uterine incision, and those with previous laparotomies besides cesarean deliveries were excluded.

\subsection{Groups of the Patients}

Patients were randomly divided into two groups. Group 1 (control group): all the patient form bladder flap. Group 2: no bladder flap was done for those patients. The patients in both groups were classified into primary and repeat cesarean deliveries.

\subsection{Study Design}

Eligible patients scheduled for cesarean deliveries were approached by one members of the research team and all patients were informed about the project's objectives before inclusion and signed consent were received from them. The patients in both groups were randomly allocated to the bladder flap group or no bladder flap group using computer-generated random numbers concealed in opaque envelops and only the surgeon was aware of the participant's groups according to the envelop. Patients were blinded to their group allocation. Patients were not told at any point during surgery or follow-up whether they were allocated to the bladder flap group or no bladder flap group.

The technique of cesarean delivery was similar in the two groups, except for omission or creation of the bladder flap. Bladder flap formation during CS created through taking a layer of the peritoneum above the upper edge of the bladder and in the anterior part of the lower uterine segment with forceps in the middle line and transected with the scalpel or scissors. Then the scissor placed between the bladder-uterine serous and the lower segment myometrium, and pressed out from the center line, and then while the blades were alternately partially opened, it was withdrawn to isolate a strip up to $2 \mathrm{~cm}$ wide from the serous, then the incision was made. As we approach the side margins on each side, the scissors were directed in part to the series. The lower flap of the peritoneum was elevated, and the bladder was slowly separated from the underlying myometrium by sharp or slow dissection [17]. In the no bladder flap group, a low-transverse uterine incision was made approximately $1 \mathrm{~cm}$ above the vesico-uterine peritoneal fold without dissection and formation of a bladder flap. Patients underwent the procedure based on their allocation unless intraoperative findings as determined by the surgeon made the alternative procedure medically necessary.

In this study, the participant's age and gestational age were recorded prior to 
surgery. The intraoperative information documented on a data collection form including incision time, delivery time, the whole length of surgery (from incision to birth and until the end of the skin suturing), creation or omission of the bladder flap, and any intraoperative complications. Also Blood loss during surgery by estimating blood amount considering the consumed blood gases and incidence of macroscopic hematuria of surgery were recorded in both groups. After the operation, the patients' charts form of the first postoperative day will be fulfilled by one of our team and again the group of the patient is unknown for him. Patients were asked to score their pain using VAS scores $(0-10)$, on a scale of 0 (no pain) to 10 (worst pain). The need for analgesic drugs during hospitalization is also documented. Immediately before removal of their Foley catheter a urine sample was collected directly through the Foley catheter and was tested with dipsticks for micro-hematuria (Negative, Trace, 1+, 2+, 3+). The hemoglobin levels were measured $48 \mathrm{~h}$ after the operation and compared with preoperative values to obtain the changes in hemoglobin. The total duration of hospital stays were recorded and all variables were compared between the two groups. At 4 - 6 weeks postoperatively, patients were contacted by the research stuff again and asked about their postoperative course, including pain score on a scale of 0 to 10 , symptoms of infection, and postoperative complications. We try to use a large sample size to gain a statistically significant primary outcome of total operating time. So for primary cesareans, we anticipate a total of 200 patients. For repeat cesarean deliveries, we anticipate 350 patients. Therefore, the total sample size was 550. Long-term effects of omitting the bladder flap were assessed in this study as 45 of our cases were followed up in the next CS. All patients were second gravid after our first caesarian section. Twenty four of them were from the group of the non-bladder flap and the other twenty one from the other group. All the cases were examined intra-operatively for the presence and the extension of the adhesion by using the classification proposed by Tulandi [18].

Selected baseline characteristics and most outcome measures were compared between the two groups using power calculation and $T$ test.

\section{Result}

A total of 550 women were enrolled from February 2017 to May 2018 (Figure 1). For primary cesareans, we anticipate a total of 200 patients (100 in each group). For repeat cesarean deliveries, we anticipate 350 patients (150 for bladder flap group and 200 for no flap group). Of the 250 patients assigned to the bladder flap group, 245 received the bladder flap, whereas 5 did not. Reasons for not creating the bladder flap were presence of sever bladder adhesion at the site of CS (n_2), need for a vertical uterine incision (n_3). Among the 300 women allocated to the no bladder flap group, the bladder flap was omitted in 290 , whereas 10 had bladder flaps created. The most common reason was presence of scar tissue $(n=9)$. Nine women in the bladder flap group, twelve in other group were lost to follow-up, yielding 236 patients in the bladder flap group and 278 in the no bladder flap group. 


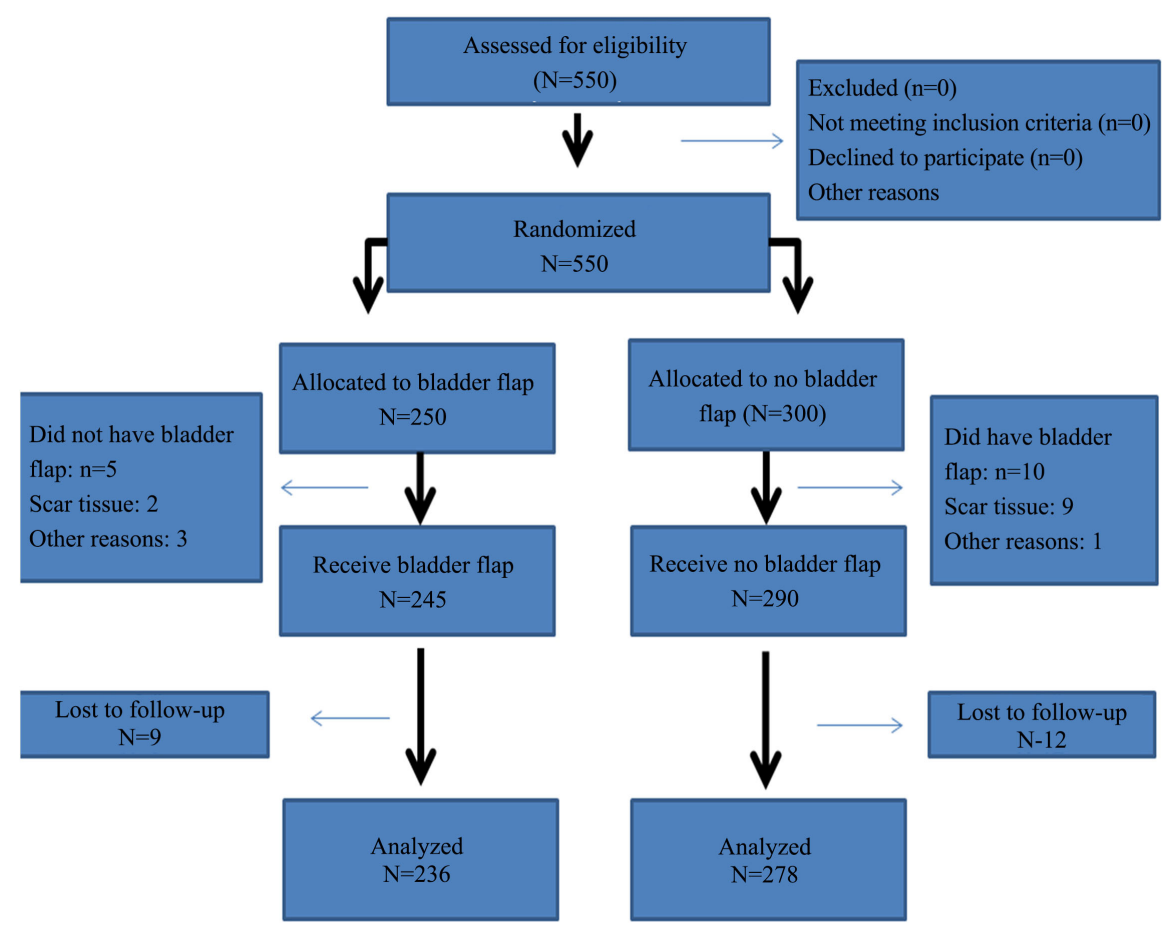

Figure 1. Flow diagram of the study participants.

\subsection{Demographic Character}

Women assigned to the bladder flap or no bladder flap group were similar regarding baseline demographic characteristics regarding to age, weight, BMI, and gestational age at time of delivery (Table 1). The mean age of women in flap group was $27.4 \pm 5.8$ years and mean maternal age in no bladder flap group was $28.4 \pm 5.9$ years $(\mathrm{p}=0.844)$. The mean gestational age in formation of bladder flap group was $38.3 \pm 1.9$ and in none formation of bladder flap group was 38.5 $\pm 1.8(\mathrm{p}=0.381)$ based on ultrasound results. Also the mean BMI in formation of bladder flap group was $29.5 \pm 9.5$ and in none formation of bladder flap group was $31.5 \pm 9.8(\mathrm{p}=0.41)$. There is no difference in parity in both groups and most common indications for cesarean delivery were elective section, failure to progress, fetal intolerance of labor, mal-presentation, twins, CPD, macrosomnia, and preeclampsia.

\subsection{Intra-Operative and Post-Operative Outcome}

Because of the large sample we present results for the combined analysis (primary and repeat cesarean deliveries) and also we present the result in each group for primary and repeated delivery.

Duration from skin incision to delivery was shorter among women assigned to the no bladder flap group compared with those in the bladder flap group. In the group with bladder flap, the time from incision to delivery was $18.4 \pm 8.67$ minute and in the group without bladder flap formation was $14.14 \pm 7.64$ minute. Differences between the two groups was significant $(\mathrm{p}=0.04)$. The total operative time of cesarean delivery in group with bladder flap was $53.8 \pm 27.09$ 
minutes and in group without bladder flap formation was $37.6 \pm 27.6$. And again the differences between total operative time in the group without bladder flap formation was significantly lower than the other group $(\mathrm{p}=0.01)$ (Table 2). When analysis was stratified into primary or repeat cesarean deliveries, similar findings were noted as the incision-to-delivery time was significantly shorter in the no bladder flap group among both primary cesarean deliveries and repeat cesarean deliveries ( $\mathrm{p}=0.02,0.01$ respectively) (Table 3 and Table 4). The same results were noted as regard to total operative time $(\mathrm{P}=0.01,0.02$ respectively).

Only one case of bladder injuries occurred in bladder flap group in repeated CS patient due to adhesion. Microscopic hematuria in two group was seen 1 day post-operative and the differences between two group was significant $(\mathrm{p}=$ 0.001 ). When analysis was stratified into primary or repeat cesarean deliveries, similar findings were noted $(\mathrm{p}=0.01,0.03$ respectively). The pain scores for first 24 hour post-operative were noted to be less in non-bladder flap group than the other group but this change were non-significant $(\mathrm{p}=0.06)$. Also the urinary tract infection shown in 15 cases compared with only 10 cases in non-bladder flap group. When analysis was stratified into primary or repeat cesarean deliveries, similar findings were noted.

In this study the number of gas consumption intraoperative in the bladder flap formation group was more than that in the none formation bladder flap group (6.2 \pm 1.5 and $5.4 \pm 1.5$ respectively) and differences between the two groups was non-significant $(\mathrm{p}=0.1)$. No significant differences in the two groups were observed in terms of decrease in hematocrit at 48 hours after cesarean compared to preoperative conditions $(\mathrm{p}=0.6)$ (Table 2) and hospital days of stay $(p=0.8)$. Also, only in one patient undergone CS with bladder flap formation uterine atone was seen other patient show sub-rectal hematoma. In other group one patient show atonic post-partum hemorrhage.

\subsection{Long-Term Outcome}

Long-term effects of omitting the bladder flap were assessed in this study as regard to adhesion site and density by using the classification supposed by Tulandi (Table 5 and Table 6). The adhesion in bladder flap formation group was significantly more than that in the none formation bladder flap group $(\mathrm{p}=0.04)$.

\section{Discussion}

This study aims to investigate the effect of formation or no-formation of bladder flap during CS. It is clear that some studies support omission of the bladder flap during cesarean delivery, but the fact is that most obstetricians prefer to create bladder flaps during a cesarean delivery. Whether this is a product of obstetricians' early training, bladder flap dissection remains a common step during routine cesarean delivery. Bladder omission may be performed by some obstetrician in some situations where rapid surgical delivery of the fetus is necessary. Given that bladder injury is one of the main concerns with bladder dissection, this method would be advantageous for the obstetrician. 
Table 1. Demographic characters of the two groups.

\begin{tabular}{|c|c|c|c|c|c|c|}
\hline \multirow[b]{2}{*}{ Character } & \multirow[b]{2}{*}{$\begin{array}{c}\text { Bladder } \\
\text { flap } \\
(\mathrm{N}=236)\end{array}$} & \multirow[b]{2}{*}{$\begin{array}{c}\text { No } \\
\text { bladder } \\
\text { flap } \\
(\mathrm{N}=278)\end{array}$} & \multicolumn{2}{|c|}{ Bladder flap } & \multicolumn{2}{|c|}{ No bladder flap } \\
\hline & & & $\begin{array}{l}\text { Primary } \\
\text { cesarean } \\
\text { Delivery } \\
(\mathrm{N}=94)\end{array}$ & $\begin{array}{c}\text { Repeated } \\
\text { cesarean } \\
\text { delivery } \\
(\mathrm{N}=142)\end{array}$ & $\begin{array}{l}\text { Primary } \\
\text { cesarean } \\
\text { delivery } \\
(\mathrm{N}=98)\end{array}$ & $\begin{array}{c}\text { Repeated } \\
\text { cesarean } \\
\text { delivery } \\
(\mathrm{N}=180)\end{array}$ \\
\hline $\begin{array}{l}\text { Maternal } \\
\text { age (y) }\end{array}$ & $27.4 \pm 5.8$ & $28.4 \pm 5.9$ & $24.4 \pm 2.8$ & $26.4 \pm 5.8$ & $24.4 \pm 5.9$ & $27.4 \pm 6.8$ \\
\hline $\begin{array}{c}\text { Maternal } \\
\text { weight }(\mathrm{kg})\end{array}$ & $88.5 \pm 20.8$ & $95 \pm 23.8$ & $90.5 \pm 21.9$ & $94.5 \pm 21.8$ & $86.5 \pm 19.7$ & $98.5 \pm 20.8$ \\
\hline $\begin{array}{c}\text { Maternal } \\
\text { BMI }\left(\mathrm{Kg} / \mathrm{m}^{2}\right)\end{array}$ & $29.5 \pm 9.5$ & $31.5 \pm 9.8$ & $27.5 \pm 7.8$ & $31.8 \pm 8.1$ & $30.5 \pm 8.8$ & $31.5 \pm 6$ \\
\hline $\begin{array}{l}\text { Gestational } \\
\text { age }(w)\end{array}$ & $38.3 \pm 1.9$ & $38.5 \pm 1.8$ & $38.0 \pm 2.9$ & $38.2 \pm 1.1$ & $38.3 \pm 2.8$ & $38.7 \pm 0.9$ \\
\hline
\end{tabular}

Table 2. Comparison of intraoperative and postoperative outcome between the two groups of cesarean section (CS) delivery with and without bladder flap formation (mean \pm standard deviation $)\left(\mathrm{p}={ }^{*}<0.05\right)$.

\begin{tabular}{|c|c|c|c|}
\hline Characteristic & $\begin{array}{l}\text { Bladder flap } \\
(\mathrm{N}=236)\end{array}$ & $\begin{array}{l}\text { No bladder flap } \\
\qquad(\mathrm{N}=278)\end{array}$ & $\begin{array}{c}P \\
(*<0.05)\end{array}$ \\
\hline Total operating time (min) & $53.8 \pm 27.09$ & $37.6 \pm 27.6$ & $0.012\left(^{*}\right)$ \\
\hline Incision-to-delivery time (min) & $18.4 \pm 8.67$ & $14.14 \pm 7.64$ & $0.04\left(^{*}\right)$ \\
\hline Bladder injury & 1 & 0 & - \\
\hline Intra-operative blood loss (gases NB) & $6.2 \pm 1.5$ & $5.4 \pm 1.5$ & 0.1 \\
\hline Other operative complication & 0 & 0 & - \\
\hline Decrease in HB \%(g/dl) $48 \mathrm{~h}$ after CS & $0.8 \pm 0.4$ & $0.7 \pm 0.5$ & 0.6 \\
\hline Micro hematuria $1^{\text {st }}$ day $(\geq+1)$ & 41 & 11 & $0.001\left(^{*}\right)$ \\
\hline Pain score $(1-10) 1^{\text {st }}$ day & $5.3 \pm 1.7$ & $3.8 \pm 1.3$ & 0.06 \\
\hline Urinary tract infection (NB of cases) & 15 & 10 & - \\
\hline $\begin{array}{l}\text { Postoperative complication (atonic uterus, } \\
\text { sup rectal hematoma, bleeding) }\end{array}$ & 2 & 1 & - \\
\hline Days of hospitalization & $1.45 \pm 0.2$ & $1.37 \pm 0.3$ & 0.8 \\
\hline
\end{tabular}

Table 3. Comparison of Surgical Times, intraoperative and postoperative outcome among Women Undergoing Primary Cesarean Deliveries $\left(\mathrm{p}={ }^{*}<0.05\right)$.

\begin{tabular}{cccc}
\hline Characteristic & $\begin{array}{c}\text { Bladder flap } \\
(\mathbf{N}=94)\end{array}$ & $\begin{array}{c}\text { No bladder flap } \\
(\mathbf{N}=98)\end{array}$ & $\begin{array}{c}\text { P } \\
(*<0.05)\end{array}$ \\
\hline Total operating time $(\mathrm{min})$ & $40.3 \pm 22.04$ & $27.6 \pm 21.07$ & $0.01\left(^{*}\right)$ \\
Incision-to-delivery time $(\mathrm{min})$ & $14.7 \pm 4.6$ & $10.7 \pm 3.09$ & $0.02\left(^{*}\right)$ \\
Bladder injury & 0 & 0 & - \\
Decrease in HB \% (g/dl) $48 \mathrm{~h}$ after CS & $0.75 \pm 0.4$ & $0.73 \pm 0.4$ & 0.2 \\
Micro hematuria $\mathbf{1}^{\text {st }}$ day & 22 & 7 & $0.01\left(^{\star}\right)$ \\
Pain score $(1-10) 1^{\text {st }}$ day & $4.3 \pm 1.3$ & $3.3 \pm 1.7$ & 0.08 \\
Urinary tract infection & 5 & 2 & 0.6 \\
Days of hospitalization & $1.5 \pm 0.2$ & $1.3 \pm 0.3$ & \\
\hline
\end{tabular}


Table 4. Comparison of Surgical Times, intraoperative and postoperative outcome among Women Undergoing Repeat Cesarean Deliveries $\left(\mathrm{p}={ }^{*}<0.05\right)$.

\begin{tabular}{cccc}
\hline Characters & $\begin{array}{c}\text { Bladder flap } \\
(\mathrm{N}=142)\end{array}$ & $\begin{array}{c}\text { No bladder flap } \\
(\mathbf{N}=180)\end{array}$ & $\begin{array}{c}\text { P } \\
(*<0.05)\end{array}$ \\
\hline Total operating time (min) & $71.6 \pm 28.75$ & $47.8 \pm 22.1$ & $0.02\left(^{*}\right)$ \\
Incision-to-delivery time (min) & $21.7 \pm 6.6$ & $15.8 \pm 5.9$ & $0.01\left(^{*}\right)$ \\
Bladder injury & 1 & 0 & - \\
Decrease in HB \% (g/dl) 48 h after CS & $0.8 \pm 0.7$ & $0.75 \pm 0.4$ & 0.09 \\
Micro hematuria $\mathbf{1}^{\text {st }}$ day & 19 & 3 & $0.03\left(^{*}\right)$ \\
Pain score (1 - 10) $\mathbf{1}^{\text {st }}$ day & $5.25 \pm 1.4$ & $4.5 \pm 0.4$ & 0.07 \\
Urinary tract infection $(\mathrm{NB}$ of cases $)$ & 10 & 8 & - \\
Days of hospitalization & $1.55 \pm 0.4$ & $1.25 \pm 0.3$ & 0.4 \\
\hline
\end{tabular}

Table 5. Classification of intra-abdominal adhesions after cesarean delivery [18].

\begin{tabular}{ccccc}
\hline Adhesions & Consistency of the adhesions & $<3 \mathrm{~cm}$ & $3-6 \mathrm{~cm}$ & $>6 \mathrm{~cm}$ \\
\hline $\begin{array}{c}\text { Between uterus } \\
\text { and bladder }\end{array}$ & Filmy & 1 & 2 & 4 \\
$\begin{array}{c}\text { Between uterus } \\
\text { and abdominal fascia }\end{array}$ & Dense & 4 & 8 & 16 \\
$\begin{array}{c}\text { Between uterus } \\
\text { and omentum }\end{array}$ & Filmy & 1 & 2 & 4 \\
$\begin{array}{c}\text { Between omentum } \\
\text { and abdominal fascia }\end{array}$ & Dense & 4 & 8 & 16 \\
Adhesions to other pelvic structure \\
that interfere with the delivery
\end{tabular}

Table 6. Comparison of long term effect between the two groups on the degree of adhesion $\left(\mathrm{p}={ }^{*}<0.05\right)$.

\begin{tabular}{cccc}
\hline Characters & $\begin{array}{c}\text { Bladder flap } \\
(\mathrm{N}=21)\end{array}$ & $\begin{array}{c}\text { No bladder flap } \\
(\mathrm{N}=24)\end{array}$ & $\begin{array}{c}\mathrm{P} \\
\left({ }^{*}<0.05\right)\end{array}$ \\
\hline Degree of adhesion & $3.3 \pm 2.6$ & $2.2 \pm 1.6$ & $0.04\left(^{*}\right)$ \\
\hline
\end{tabular}

Some of the important factors in the success of CS are the time from skin incision to delivery of the fetus. According to the results of this study, the time required for skin incision and removal of fetus and the total operative time at cesarean delivery in the case group (no bladder flap) were significantly less than the control group (bladder flap). The Hohlagschwandtner' study and O'Neill 'study in this regard are in line with that of our study [14] [15]. However, Tuuli show that the time required for skin incision and removal of a fetus reduced by omission of the bladder flap; however, the total time of CS has not reduce [19]. 
We included both primary and repeat cesarean deliveries and enrolled a more diverse group of patients, making our results potentially more generalizable also enabled us estimate whether the benefits or risks of omitting the bladder flap differ for primary and repeat cesarean deliveries. Another strength of our study is that the two groups were similar regarding baseline characteristics.

The lower rate of postoperative micro-hematuria in our study in the first group also reflects a reduced manipulation and trauma of the urinary bladder. The same result was shown in the previous study [20].

In this study, the amount of bleeding during operation was assisted through number of gases used during CS and also through drop in the hematocrit 48 hour post-operative. As a result, in the group without a bladder flap, the bleeding and the drop in hematocrit were lower than another group but they were insignificant. The findings of this study were consistent with findings of the meta-analyzes conducted on the results of three other clinical trial studies. All of them state that the flap omission has no significantly effect on the bleeding [14].

Postoperative pain reduction and the subsequent reduction in the need for analgesics (pethidine and diclofenac) was observed in this study. This is may be due to reduced trauma to the patient during surgery. Previous study by Hohlagschwandtner achieved similar results [14].

In this study, no difference in postoperative hospitalization stay was seen when the study group was compared with the control group. The number of days of hospitalization may be influenced by many factors other than formation of bladder flaps such as postoperative cares and medical condition of the patient.

As for long-term effects of omitting the bladder flap were also assessed in this study, however only 45 of our cases were followed up in the next CS. The cause of small sample size that all the patients were from the group of primary CS in order to be sure of the cause of the adhesion not due to multiple CS. We use Tulandi adhesion scaled in the comparing the effect of omitting the bladder flap on the adhesion in the next CS. The cases in group of no-bladder flap associated with significantly fewer adhesions than the cases from the other group. The adhesion in the non-bladder flap group was also filmy and present usually between uterus and omentum and usually small in size $(<3 \mathrm{~cm})$. The study done by Malvasi reported also the decreased adhesions and sub-mesothelial fibrosis at subsequent cesarean delivery when the bladder flap was omitted which is matching with our result [21]. This can be explained by the omission of the bladder flap causes less trauma and vascular injury, subsequently fewer additional hemostatic sutures are required.

One limitation of our study is that we didn't comment on the non-formation of bladder flap in obstructed labor. Extension of the uterine incision into the broad ligament and lower segment during delivery of the fetal head typically occurs in advanced labor when the lower segment is thin and the fetal head is deeply engaged. Non-formation of bladder flap in this situation can result in bladder tear. 
Finally, our study, like the other trial was not powered to assess the effect of omitting the bladder flap on bladder injury. Although there were no cases of bladder injury, the low incidence of bladder injury during cesarean delivery means an impractically large sample size would be required to detect any differences [15]. However, other reports have linked difficulty encountered while creating the bladder flap, rather than its omission, as the risk factor for bladder injury at cesarean delivery [22].

\section{Conclusion}

To conclude our result, the omission of the bladder flap at CS has short and long-term benefits. The short term benefits include reduction of operating time and incision-delivery interval, reducing the severity of intraoperative bleeding and postoperative hematocrit reduction. In addition, it is associated with good long-term outcomes with regards to adhesion. These findings, together with results of another study, may argue against the practice of routinely creating the bladder flap at cesarean deliveries in the absence of a specific indication for bladder dissection.

\section{Conflicts of Interest}

The authors declare no conflicts of interest regarding the publication of this paper.

\section{References}

[1] Witt, W.P., Wisk, L.E., Cheng, E.R., et al. (2015) Determinants of Cesarean Delivery in the US: A Life Course Approach. Maternal and Child Health Journal, 19, 84-93. https://doi.org/10.1007/s10995-014-1498-8

[2] Menacker, F., Declercq, E. and Macdorman, M.F. (2006) Cesarean Delivery: Background, Trends, and Epidemicology. Seminars in Perinatology, 30, 235-241. https://doi.org/10.1053/j.semperi.2006.07.002

[3] Liu, S., Rusen, I.D., Joseph, K.S., et al. (2004) Recent Trends in Caesarean Delivery Rates and Indications for Caesarean Delivery in Canada. Journal of Obstetrics and Gynaecology Canada, 26, 735-742. https://doi.org/10.1016/S1701-2163(16)30645-4

[4] Wood, R.M., Simon, H. and Oz, A.U. (1999) Pelosi-Type vs. Traditional Cesarean Delivery. A Prospective Comparison. Journal of Reproductive Medicine, 44, 788-795.

[5] Berghella, V., Baxter, J.K. and Chauhan, S.P. (2005) Evidence-Based Surgery for Cesarean Delivery. American Journal of Obstetrics \& Gynecology, 193, 1607-1617. https://doi.org/10.1016/j.ajog.2005.03.063

[6] Wilkinson, C. and Enkin, M.W. (2000) Uterine Exteriorization versus Intraperitoneal Repair at Caesarean Section. Cochrane Database of Systematic Reviews, No. 2, CD000085.

[7] Ramsey, P.S., White, A.M., Guinn, D.A., Lu, G.C., Ramin, S.M., Davies, J.K., et al. (2005) Subcutaneous Tissue Reapproximation, Alone or in Combination with Drain, in Obese Women Undergoing Cesarean Delivery. Obstetrics \& Gynecology, 105, 967-973. https://doi.org/10.1097/01.AOG.0000158866.68311.d1 
[8] Coutinho, I.C., Ramos de Amorim, M.M., Katz, L. and Bandeira de Ferraz, A.A. (2008) Uterine Exteriorization Compared with in Situ Repair at Cesarean Delivery: A Randomized Controlled Trial. Obstetrics \& Gynecology, 111, 639-647. https://doi.org/10.1097/AOG.0b013e31816521e2

[9] Nisenblat, V., Barak, S., Griness, O.B., Degani, S., Ohel, G. and Gonen, R. (2006) Maternal Complications Associated with Multiple Cesarean Deliveries. Obstetrics \& Gynecology, 108, 21-26. https://doi.org/10.1097/01.AOG.0000222380.11069.11

[10] Morales, K.J., Gordon, M.C. and Bates Jr., G.W. (2007) Postcesarean Delivery Adhesions Associated with Delayed Delivery of Infant. American Journal of Obstetrics \& Gynecology, 196, 461e1-6. https://doi.org/10.1016/j.ajog.2006.12.017

[11] Phipps, M.G., Watabe, B., Clemons, J.L., Weitzen, S. and Myers, D.L. (2005) Risk Factors for Bladder Injury during Cesarean Delivery. Obstetrics \& Gynecology, 105, 156-160. https://doi.org/10.1097/01.AOG.0000149150.93552.78

[12] Faricy, P.O., Augspurger, R.R. and Kaufman, J.M. (1978) Bladder Injuries Associated with Cesarean Section. Journal of Urology, 120, 762-763. https://doi.org/10.1016/S0022-5347(17)57354-1

[13] Eisenkop, S.M., Richman, R., Platt, L.D. and Paul, R.H. (1982) Urinary Tract Injury during Cesarean Section. Obstetrics \& Gynecology, 60, 591-596.

[14] O’Neill, H.A., Egan, G., Walsh, C.A., Cotter, A.M. and Walsh, S.R. (2014) Omission of the Bladder Flap at Caesarean Section Reduces Delivery Time without Increased Morbidity: A Meta-Analysis of Randomised Controlled Trials. European Journal of Obstetrics \& Gynecology and Reproductive Biology, 174, 20-26.

https://doi.org/10.1016/j.ejogrb.2013.12.020

[15] Hohlagschwandtner, M., Ruecklinger, E., Husslein, P. and Joura, E.A. (2001) Is the Formation of a Bladder Flap at Cesarean Necessary? A Randomized Trial. Obstetrics \& Gynecology, 98, 1089-1092. https://doi.org/10.1097/00006250-200112000-00017

[16] Murphy, K. (1999) Reducing the Complications of Cesarean Section. In: Bonnar, J. (Ed.), Recent Advances in Obstetrics and Gynaecology, Churchill Livingstone, London, 144.

[17] Cunningham, F.G. and Williams, J.W. (2010) Williams Obstetrics. In: Cunningham, F.G., Leveno, K.J., Bloom, S.L., Hauth, J.C., Rouse, D. and Spong, C., Eds., Cesarean Delivery and Peripartum Hysterectomy, 23rd Edition, McGraw-Hill, New York, 544-564.

[18] Tulandi, T. and Lyell, D.J. (2013) Classification of Intra-Abdominal Adhesions after Cesarean Delivery. Gynecological Surgery, 10, 25-29. https://doi.org/10.1007/s10397-012-0765-1

[19] Tuuli, M.G., Odibo, A.O., Fogertey, P., Roehl, K., Stamilio, D. and Macones, G.A. (2012) Utility of the Bladder Flap at Cesarean Delivery: A Randomized Controlled Trial. Obstetrics \& Gynecology, 119, 815-821. https://doi.org/10.1097/AOG.0b013e31824c0e12

[20] Chigbu, C., Ezeome, I. and Iloabachie, G. (2006) Non-Formation of Bladder Xap at Cesarean Section. International Journal of Gynecology \& Obstetrics, 95, 284-285. https://doi.org/10.1016/j.ijgo.2006.08.010

[21] Malvasi, A., Tinelli, A., Guido, M., Cavallotti, C., Dell'Edera, D., Zizza, A., et al. (2011) Effect of Avoiding Bladder Flap Formation in Caesarean Section on Repeat Caesarean Delivery. European Journal of Obstetrics \& Gynecology and Reproductive Biology, 159, 300-304. https://doi.org/10.1016/j.ejogrb.2011.09.001 
[22] Rahman, M.S., Gasem, T., Al Suleiman, S.A., Al Jama, F.E., Burshaid, S. and Rahman, J. (2009) Bladder Injuries during Cesarean Section in a University Hospital: A 25-Year Review. Archives of Gynecology and Obstetrics, 279, 349-352.

https://doi.org/10.1007/s00404-008-0733-1 